\title{
EFFECT OF COMPONENTS ON A SOLAR PANEL SYSTEM EFFICIENCY
}

\author{
Özge Demir Başak ${ }^{1}$, Bekir Sami Sazak ${ }^{2}$ \\ ${ }^{1}$ University of Muğla Sitkı Koçman, Department of Electric and Energy, Muğla, Turkey \\ ${ }^{2}$ University of Pamukkale, Faculty of Engineering, Department of Electrical and Electronic Engineering, Denizli,
} Turkey

\begin{abstract}
Photovoltaic panels have some disadvantages such as high prices and unsatisfactory efficiencies. Studies about photovoltaic system efficiency have become important for decreasing total panel costs. Photovoltaic system's efficiency depends on both panel structure and system components. System components changes with the characteristics of the system and includes electrical components, like accumulators, inverters, charge controllers, as well as solar cell structures like cell shape or cell material. To increase the efficiency of the system some components such as cooling systems, concentrators or sun tracking systems may integrate to photovoltaic system. This paper examines the components which increases the efficiency of a system mostly. Additionally optimum efficiency increasing components suggested with examples for different regions.
\end{abstract}

Keywords: Cooling, Efficiency, Photovoltaic, Renewable Energy systems, Solar cell system

\section{INTRODUCTION}

First photovoltaic cell made by Wilougby Smith in 1873 and the first silicon solar cell was developed at Bell Laboratories in 1954 [1]. After late 1960s first studies about amorphous silicon cells published [2, 3]. In the past 30 years, the demand for solar energy has grown consistently with growth rates of $20-25 \%$ per year [4].

Nowadays photovoltaic panels have become a popular topic because while panel costs are decreasing, efficiencies of panels are increasing steadily. Photovoltaic panels did not attract attention till 1970s but today they are also seen as a solution for environmental damages of fossil fuels. Photovoltaic panels can be used to generate electricity at small, medium or large scale.

A photovoltaic system's main parts are photovoltaic panel, charge controller, accumulators and inverter. Efficiency variation of each part affects the whole system efficiency. In order to increase efficiency of solar panel, some extra components like sun tracking systems, cooling units or concentrators may be added to the system.

In this paper initially the main components of a standalone photovoltaic system examined. After examining the efficiency increasing components using in a photovoltaic system, these components analyzed in comparison with each other and also examples were given about for different regions to choose the most appropriate component.

\section{COMPONENTS OF A PV SYSTEM}

There are many factors affecting the efficiency and one of them is components which constitutes photovoltaic system like solar panel and electrical components. Sun tracking systems, cooling units and concentrators are the other components which are using for increasing the efficiency of solar panel. Fig.1 shows the arrangement of the main components of a standalone system. In a grid connected system, using charge controller and accumulators is investors' preference.

\subsection{Solar Panel and Panel Structure}

A solar panel is the component which generates electricity by photo-electric reaction. The sun spreads out photons, when these photons reach the solar cell free electrons on the $\mathrm{N}$ type silicon rush to $\mathrm{P}$ type silicon to fill the free holes and electricity is produced by the movement of electrons. Solar panels, modules and arrays may be formed by combining solar cells. There are many types of solar cells with different efficiencies.

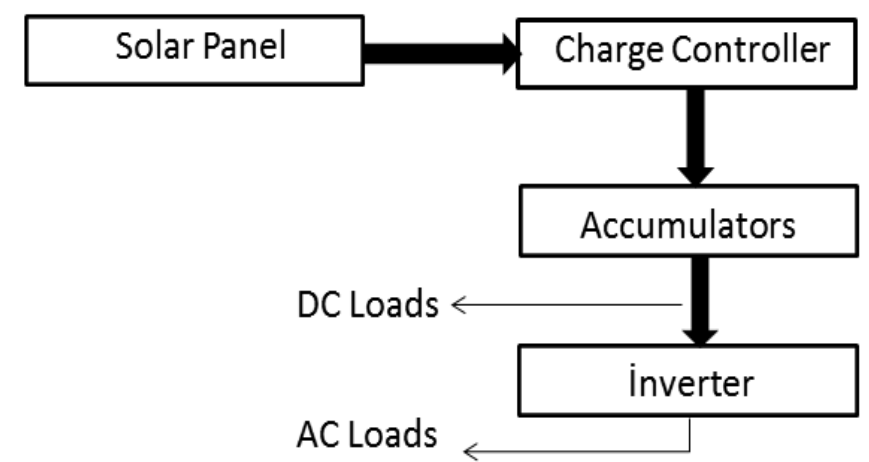

Fig.1 Arrangement of the components of a standalone system [5] 


\subsection{Electrical Components}

In a standalone system, electrical components include charge controller, accumulators and inverter which affect the efficiency of a photovoltaic system. Additionally cabling losses, which can be assumed 1-3\% must observe while calculating the efficiency [6].

a. Charge Controller: A charge controller limits the current which transmitted to accumulators or taken from accumulators. Thus prevents performance drops or prevents shortening the life of battery which caused by overcharging or over voltage. Today charge controllers are using with PWM or MPPT technologies.

b. Accumulators: Accumulators are using to store energy at the places where are far from interconnected networks or at the places where an uninterruptible power supply is needed. Using accumulators are not necessary if photovoltaic system directly connects to the grid.

c. Inverter: At photovoltaic systems inverters are placed between accumulators and AC loads to convert DC power to AC. Alternating current which converted at inverter can be adjusted by transformers, switching and controlling circuits.

\subsection{Other Components to Increase Efficiency}

In this section components which can be added to photovoltaic system subsequently to increase the efficiency are discussed. Active components use a portion of the electricity which generated by photovoltaic panel, but usually these components contribution to the efficiency are greater than the energy they expend, while passive components does not need energy. Sun tracking systems, cooling units and concentrators are the components using for increasing the efficiency.

a. Sun Tracking Systems: Sun tracking systems tracks the sun for ensuring sun rays fall perpendicular to panel surface from sunrise to sunset. Sun tracking systems can be added to photovoltaic system both in project phase or subsequently. One of the projects, which sun tracking system added subsequently made in Kazakhstan and system power increased from $375 \mathrm{~W}$ to 500W[7]. Sun tracking systems can be classified in two groups as electronic (active) and mechanical (passive) sun tracking systems

b. Cooling Units: Temperature increase of $1{ }^{\circ} \mathrm{C}$ on PV cells will cause to $0.4-0.5 \%$ electricity efficiency decrease for crystalline $\mathrm{Si}$ based cells $[8,9]$ and $0.25 \%$ for amorphous silicon cells [10]. Using cooling units may be a solution for increasing the efficiency of a photovoltaic system. Cooling systems can be classified as active and passive cooling units

c. Concentrators: To increase efficiency, concentrators concentrate sunlight onto a small are on photovoltaic panel by lenses or mirrors. The goal is significantly reducing the cost of electricity generated by photovoltaic panels by replacing less expensive optical material with expensive semiconductors [11]. Fresnel Lenses, Parabolic Dish and Linear Parabolic are the names of existing concentrator.

\section{MOST EFFECTIVE COMPONENT TO INCREASE EFFICIENCY}

Information about the components to increase the efficiency of a photovoltaic system given before, in this section most effective component to increase efficiency is discussed without considering the costs. In photovoltaic system efficiency increasing components may be used alone or in combination. To increase productivity whether the investor will use efficiency increasing components or not, depends on the cost of the components or the amount of money to spend. Component effect on efficiency varies by region especially by temperature.

Examining photovoltaic systems with same output power and same panel structure in same region with different efficiency increasing components can give an idea about the most effective component, but with this method a literally accurate result cannot be obtained because many factors affect the efficiency of panel. Different environmental conditions, shading, different electrical components also affect the efficiency of panel, besides the effect of output power. Photovoltaic panels with higher output power are formed by more juxtaposed photovoltaic cells, and temperature increase on these panels would be more comparing small photovoltaic panels.

When photovoltaic cells with high efficiency are used in combination with efficiency increasing components, increase in efficiency would be higher compared with ordinary photovoltaic cells. Furthermore, some components like concentrators are usually used with sun tracking systems, cooling units and multijunction photovoltaic cells with high efficiency. Because of the complexity while choosing the most effective component on efficiency, the solution has been sought by comparing the components with each other.

Electronic (Active) sun tracking systems use some of the energy which produced by panels while mechanical (Passive) sun trackers does not need energy. Energy expenditure of the added component has direct impact on total panel efficiency but passive sun trackers has some disadvantages like starting each new day in a wrong position and not seeing the full sun while positioning [12], so in this study only active sun tracking systems will participate in comparing.

Passive cooling units usually uses at small scale applications or at the places where location and facilities are appropriate. Low wind strength and high temperature, limits the usage of passive cooling system. Active cooling systems spend some of the energy generated by photovoltaic panels, the reason of their often preference is, environmental conditions less affect to efficiency and their usage conditions do not limit 
by environmental conditions. In this study active cooling systems are used in comparison due to a wide variety of usage.

Fresnel lenses are the primary concentrators [13]. Parabolic dish concentrators and linear concentrators can used with heat based solar systems as well as photovoltaic systems. There are other concentrator types designed which have not classified, such as V-through PV concentrator [14]. In this study components which increases the efficiency of a photovoltaic system mostly will be chosen, so the most effective concentrator type to increase efficiency will be explored and compared with other efficiency increasing components.

\subsection{Comparing Sun Tracking Systems with Cooling}

\section{Units}

Active sun tracking systems are examined in two groups;

- $\quad$ Single axis sun tracking systems,

- Two axis sun tracking systems.

Two axis sun trackers are expensive than single axis sun trackers, but their efficiencies are higher because they can track the sun both from north to the south and east to the west. In this study, the initial setup costs of the system are not taken into consideration so two axis sun tracking system will be taken to comparison.

A two axis sun tracking system which daily energy consumption rate to daily energy production is $0.14 \%$, produces $45 \%$ more energy than the fixed mount [15]. In another study conducted in 2004 a two-axis tracking system increased the total daily energy collection by approximately $41.34 \%$ compared with that obtained from a fixed surface tilted at 32o towards the south [16].

To increase the efficiency of a photovoltaic system it is necessary to cool the module because each $1^{\circ} \mathrm{C}$ temperature increases on a photovoltaic module at $25^{\circ} \mathrm{C}$ causes power decrease up to $0.4-0.5 \%$ [17]. Active cooling units are examined in two groups;

- $\quad$ Air cooled systems

- Water or refrigerant liquid cooled systems

Air cooled systems cannot be used in every region and on every system, because if the air temperature is above $20^{\circ} \mathrm{C}$, effectiveness for PV cooling would be very low [18]. Water or refrigerant liquid cooled systems has no such a limitation so, in this study only water or refrigerant liquid cooled systems will take into consideration while comparing.

Increase in efficiency while using an active cooling unit depends on environmental temperature, design of cooling unit and the material of photovoltaic cell. A design by Akbarzadeh and Wadowski shows that cooling the solar photovoltaic panel with water increases the solar cells output power by almost 50\% [19]. Another technique for PV cooling is using water flow over the upper surface of the PV cells, this technique increases the efficiency by $10.3 \%$
[20].If solar tracking units and cooling units are compared with each other, it can be said that well-designed sun tracking systems effect on efficiency is approximately $40 \%$ and cooling unit's effect is variable between 1-50\%. In this case it can be said that in cold or windy regions choosing a sun tracking system instead of cooling unit would increase the efficiency mostly, but in hot regions a well-designed active cooling system would be more effective.

\subsection{Comparing Sun Tracking Systems with}

\section{Concentrators}

Efficiency increase of a photovoltaic system with concentrators is directly associated with the structure of photovoltaic cell and concentrators are usually used with cooling units, high efficient photovoltaic cells and sun tracking systems so, it is hard to estimate the effect of concentrator to efficiency. Performing the measurements under STC would be more accurate because of environmental variability.

The Martin Marietta point focus Fresnel system is the first generation of concentrators with Fresnel lenses and had a efficiency increase about $9-10 \%$ in 1978[21] than Intersol improved the performance to $15 \%$ by 1984 [22]. These early experiments with concentrators were performed under laboratory conditions but nowadays concentrator applications are applied with cooling units, high efficient photovoltaic cells or sun tracking systems.

Assuming in a photovoltaic system which uses only concentrators with ordinary photovoltaic cells increase in the efficiency is approximately $15 \%$, it is clear that choosing sun tracking systems which increases the efficiency about $40 \%$ would be more accurate.

\subsection{Comparing Cooling Units with Concentrators}

Concentrated sunlight which reflected on a photovoltaic cell also brings overheating problem, to overcome this problem concentrators and cooling units often work together.

The variability of the environmental factors, cooling unit and photovoltaic cell structure, causes cooling units exhibit different performance in a range of $1-50 \%$, while concentrators which increase the efficiency approximately $15 \%$ with ordinary photovoltaic cells. When concentrators and active cooling units using water or refrigerant liquid independently examined, it can be said that a well-designed cooling unit is preferable to a concentrator.

\section{CHOOSING OPTIMUM COMPONENT FOR DIFFERENT REGIONS}

As described in Chapter III, environmental factors affect both photovoltaic cell efficiency and efficiency increasing components' performance. When environmental factors that affect the performance of photovoltaic components are classified by region, the temperatures' effect on the performance of the components highlighted. For example in cold regions the effect of concentrators will increase, while 
cooling units' effect decrease. Similarly in regions which are close to pole, sun tracking components' effect would not be as much as at the regions which are close to equator because movements of the Sun are faster in equator than in the poles.

\subsection{Sun Tracking Systems}

Sun tracking systems are capable to track the Sun for providing falling sun light perpendicular to panel surface all day. At high latitudes increase in efficiency would not be as much as lower latitudes because at high latitudes movement of the Sun is slower than lower latitudes. But increase in efficiency while using sun tracking systems do not only depend on latitudes, design of a sun tracking system also significantly affect the increase in efficiency for example, a sun tracking system which was tested in Taiwan increases power generation approximately $24.5 \%$ than the fixed mount $\varnothing<50^{\circ}$ [23]. Another study made in Amman-Jordan says output power increased about $30-45 \%$ compared with $32^{\circ}$ fixed photovoltaic cells [24]. A PLC controlled sun tracking system designed in Syria had more than $20 \%$ power gain increase [25] and another PLC controlled study made in Turkey by using multi-axis solar trackers had increased the energy by $42.6 \%$ [26].

\subsection{Cooling Units}

The effect of cooling units to photovoltaic system described in Chapter 3, efficiency obtained from a photovoltaic panel which uses cooling unit changes according to ambient temperature hence it can be said that cooling units' effect vary by region. In very cold regions cooling unit effect cannot be as much as mid-latitude regions because in very cold regions photovoltaic panels do not require cooling. In very hot regions if circulating water or refrigerant liquid which gained heat from photovoltaic panel, cannot lose enough heat before re-entering circulation the investor would not get the expected efficiency increase.

A study made in Sydney Australia shows that heat loss by convection between water and the PV panel's upper surface, makes an increase of about $15 \%$ [20] while another study made in China says, at $15^{\circ} \mathrm{C}$ air temperature the change in electricity and thermal gains is less than 1\% [27]. Thus, design of the cooling unit has a great importance along with environmental temperature.

\subsection{Concentrators}

The variability of concentrators' effect on efficiency was mentioned above; environmental factors also affect efficiency increase in photovoltaic cells which use concentrators. Increase in efficiency would be more at high radiated regions, but concentrators also increase the temperature on photovoltaic panel so, if a concentrator will not be used in conjunction with cooling unit, to increase the total efficiency, panel temperature and concentration ratio should be kept in balance.

Sandia National Laborites made a concept design at New Mexico and had 20\% efficiency by using Fresnel lenses [28] but in generally concentrators cannot be regarded independent from cooling units.

\section{CONCLUSION}

Humanity has begun to show interest in renewable energy sources in order to obtain clean energy in last few decades; growing interests to renewable energy resources also brought attention in photovoltaic panels. Today photovoltaic panel technology is still at developing period; one of the biggest problems on photovoltaic panels is increasing the efficiency of photovoltaic panel. There are many factors which the effect efficiency of a photovoltaic panel, some components like sun tracking systems, cooling units and concentrators are developed to increase efficiency. All of these components can be used in a combination but in some cases the budget allocated for photovoltaic system does not allow this. In such cases the investor should decide for the component used in photovoltaic system. The extra efficiency obtained by efficiency increasing components varies by the operation region and design of the efficiency increasing component. But according to the design a well-designed active two axis sun tracking system can provide up to $40 \%$ extra efficiency independent from region. Also cooling units increase the efficiency in a range of $1-50 \%$ but due to environmental conditions $50 \%$ efficiency increase cannot be seen all the time. Concentrators are generally do not use alone because they increase the temperature on photovoltaic panel. If concentrators used alone, the efficiency increase they bring about would be unsatisfactory compared with other components. According to this information, it can be said that, first of all, the investor should investigate the most suitable sun tracking system for the photovoltaic panels which are intended to build.

\section{ACKNOWLEDGEMENTS}

The research was supported by 2013KRM024 PAUBAP project Pamukkale University, Turkey.

\section{REFERENCES}

[1]. D.M. Chapin, C.S. Fuller, G.L. Pearson, J. Appl. Phys. 25 (1954) 676.

[2]. R.C. Chittick, J.H. Alexander, H.F. Sterling, J. Electrochem. Soc. 116 (1969) 77

[3]. W.E. Spear, P.G. LeComber, J. Non-Cryst. Solids 8 (1972) 727

[4]. Spanggaard, H., \& Krebs, F. C. (2004). A brief history of the development of organic and polymeric photovoltaics. Solar Energy Materials and Solar Cells, 83(2), 125-146.

[5]. Basak, O. D., \& Sazak, B. S. (2013, October). Effect of developments on a PV system efficiency. In Electrical and Electronics Engineering (ISEEE), 2013 4th International Symposium on (pp. 1-6). IEEE.

[6]. Deniz, E. Güneş Enerjisi Santrallerinde Kayiplar.

[7]. Lee, C. Y., Chou, P. C., Chiang, C. M., \& Lin, C. F. (2009). Sun tracking systems: a review. Sensors, 9(5), 38753890.

[8]. Brinkworth et al. Thermal regulation of photovoltaic cladding. Solar Energy 1997;61:169-78.

[9]. Kranter et al. Combined photovoltaic and solar thermal systems for façade integration and building insulation. Solar Energy 1999;67:239-48. 
[10]. Kalogirou SA, Tripanagnostopoulos Y. Hybrid PV/T solar systems for domestic hot water and electricity production. Energy Convers Manage 2006;47:3368-82.

[11]. Swanson, R. M. (2003). Photovoltaic concentrators. Handbook of photovoltaic science and engineering, 449503.

[12]. Clifford, M. J., \& Eastwood, D. (2004). Design of a novel passive solar tracker.Solar Energy, 77(3), 269-280.

[13]. Andreev, V. M., Grilikhes, V. A., Khvostikov, V. P., Khvostikova, O. A., Rumyantsev, V. D., Sadchikov, N. A., \& Shvarts, M. Z. (2004). Concentrator PV modules and solar cells for TPV systems. Solar energy materials and solar cells, 84(1), 3-17.

[14]. Sangani, C. S., \& Solanki, C. S. (2007). Experimental evaluation of V-trough (2 suns) PV concentrator system using commercial PV modules. Solar energy materials and solar cells, 91(6), 453-459.

[15]. Kandemir, B. A. S. Ç. E., \& beşer, b. E. Güneş panellerinin üretim kapasitesini arttiracak güneşi takip edebilen güneş panel sisteminin prototipi.

[16]. Lee, C. Y., Chou, P. C., Chiang, C. M., \& Lin, C. F. (2009). Sun tracking systems: a review. Sensors, 9(5), 38753890 .

[17]. Thomas, R., Fordham, M., 2001. Photovoltaics and Architecture, Spon Press, London and Newyork

[18]. Kalogirou SA, Tripanagnostopoulos Y. Hybrid PV/T solar systems for domestic hot water and electricity production. Energy Convers Manage 2006;47:3368-82.

[19]. A. Akbarzadeh, T. Wadowski Heat-pipe-based cooling systems for photovoltaic cells under concentrated solar radiation

Appl Therm Eng, 16 (1) (1996), pp. 81-87

[20]. Odeh, S., \& Behnia, M. (2009). Improving photovoltaic module efficiency using water cooling. Heat Transfer Engineering, 30(6), 499-505.

[21]. Swanson, R. M. (2003). Photovoltaic concentrators. Handbook of photovoltaic science and engineering, 449503.

[22]. Edenburn M, Boes E, "Photovoltaic Concentrators: Performance and Reliability Data and Future Design Directions", IEEE Photovoltaic Specialists Conference, 473-481 (1984).

[23]. Huang, B. J., \& Sun, F. S. (2007). Feasibility study of one axis three positions tracking solar PV with low concentration ratio reflector. Energy conversion and management, 48(4), 1273-1280.

[24]. Abu-Khader, M. M., Badran, O. O., \& Abdallah, S. (2008). Evaluating multi-axes sun-tracking system at different modes of operation in Jordan. Renewable and sustainable energy reviews, 12(3), 864-873.

[25]. Al-Mohamad, A. (2004). Efficiency improvements of photo-voltaic panels using a Sun-tracking system. Applied Energy, 79(3), 345-354.

[26]. Sungur, C. (2009). Multi-axes sun-tracking system with PLC control for photovoltaic panels in Turkey. Renewable Energy, 34(4), 1119-1125.

[27]. Chow, T. T. (2003). Performance analysis of photovoltaic-thermal collector by explicit dynamic model. Solar Energy, 75(2), 143-152.
[28]. Ryu, K., Rhee, J. G., Park, K. M., \& Kim, J. (2006). Concept and design of modular Fresnel lenses for concentration solar PV system. Solar Energy, 80(12), 15801587. 